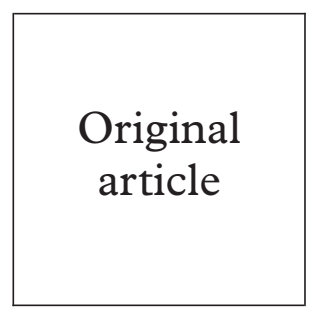

\title{
Sexually transmitted infections among HIV seropositive men and women
}

\author{
Seth C Kalichman, David Rompa, Marjorie Cage
}

Objectives: To determine the prevalence of identified STIs and recognised symptoms of STIs and their association with health status, substance use, and sexual risk behaviour in a sample of HIV seropositive men and women.

Methods: 223 men, 112 women, and five transsexual people living with HIV infection completed confidential surveys. Participants were recruited through community based services, community health clinics, and snowball (chain) recruitment techniques in Atlanta, GA, USA in December 1999.

Results: We found that (263) $78 \%$ of participants had been sexually active in the previous 3 months. For the entire sample, $42(12 \%)$ participants reported an STI in the past 3 months and $40(11 \%)$ experienced symptoms of an STI without indicating a specific diagnosis in that time. Gonorrhoea, chlamydia, syphilis, and newly diagnosed herpes simplex virus (HSV) were identified at similar rates among men, whereas trichomonas, gonorrhoea, and newly diagnosed HSV occurred most often in women. STIs were associated with substance use in men and women, with "crack" cocaine users having the greatest likelihood of an STI relative to non-crack users. STIs were also associated with continued practice of sexual risk behaviours.

Conclusions: This sample of people living with HIV-AIDS reported high rates of diagnoses and symptoms of STIs. There were significant associations between STIs, substance use, and continued high risk sexual practices in men and women. These findings support the need for studies that confirm prevalence of STIs using clinical laboratory tests.

(Sex Transm Inf 2000;76:350-354)

Keywords: HIV; sexual risk; HIV transmission

\section{Introduction}

We report the prevalence and correlates of self reported sexually transmitted infections (STIs) in a sample of HIV infected men and women. HIV infection is most frequently transmitted through unprotected anal and vaginal intercourse with an HIV infected partner. In addition, individuals who are unaware of their own HIV infection unknowingly transmit the virus to others during unprotected sex acts. As many as one in three HIV infected people continue to practise unprotected anal and vaginal intercourse after knowing that they are HIV positive, and unprotected sex often occurs with unknown serostatus or known HIV negative partners. ${ }^{1-3}$ Several STI epidemics are well documented in populations at risk for HIV, ${ }^{45}$ suggesting that STIs may also be prevalent in HIV infected people who continue to practise sexual risk behaviours. In addition, previous research has shown rates of incident STIs in people living with HIV infection that vary from $15 \%$ to $25 \%$, depending on time intervals and inclusion criteria. ${ }^{6-8}$ STIs are known to complicate the course of HIV disease progression and facilitate HIV transmission during unprotected sex acts. ${ }^{9}{ }^{10}$ Estimating the prevalence of STIs in HIV seropositive men and women can therefore provide important information for screening people with HIV-AIDS for STIs, targeting and planning interventions to reduce the spread of HIV, and forecasting trends in HIV infections. Towards this end, we report the point prevalence of identified STIs as deter- mined by self reporting in a community recruited sample of HIV infected men and women. We also examined demographic characteristics, health status markers, alcohol and other drug use, and sexual practices among HIV positive men and women with self reported STIs.

\section{Methods}

PARTICIPANTS

Study participants were $223(66 \%)$ men, 112 $(33 \%)$ women, and five (1\%) transsexuals. Because of the small number of transsexuals who had not undergone male to female sexual reassignment, we combined these participants with males for all further analyses. All participants were fluent English speakers.

\section{PROCEDURES}

Men and women were recruited from AIDS service organisations, healthcare providers, social service agencies, community residences for people living with HIV-AIDS, and infectious disease clinics in Atlanta, GA, USA, in December 1999. Flyers announcing the study opportunity were put in these locations and providers were asked to refer clients to participate in a 9 month prospective cohort study of HIV sexual transmission risk behaviour in people living with HIV-AIDS. Interested people phoned the research programme offices using a toll-free number to schedule an appointment to participate. Individuals were told that they would be asked to complete a confidential 
survey and interview concerning their health and sexual behaviours. Participants were informed that their HIV status would need to be verified by presenting a photo ID and proof of their HIV status (for example, HIV positive test result, HIV clinic card, or HIV medication prescription bottle). Participants completed informed consent in accordance with IRB guidelines, followed by an assessment of reading ability and the study measures. Participants who either demonstrated difficulty on a reading literacy test, or were unable to read the written survey, or who requested assistance were interviewed to complete all study measures. Participants were given $\$ 30$ and were asked to tell their friends and other people they knew who have HIV about the study to increase word of mouth recruitment.

\section{MEASURES}

Participants completed all study measures in a single session that consisted of: (1) demographic and health characteristics; (2) occurrences of STIs and STI symptoms; (3) substance use; and (4) sexual behaviours. Measures were self administered except for participants who experienced difficulty reading or requested assistance, for which measures were administered in an interview.

\section{Demographic and health status}

Participants were asked their age, years of education completed, income level, and their self identified sex, ethnicity, and sexual orientation. We also asked what month and year participants tested HIV seropositive, whether they had experienced each of 15 HIV related symptoms (including persistent respiratory problems, skin rashes, digestive problems, recurring fever, and fatigue), whether they had been diagnosed with an AIDS case defining condition, the number of times they have been hospitalised for HIV-AIDS related conditions, and whether they had been treated for mental health problems. We also asked participants whether they had been diagnosed with an AIDS related condition, and if so which diagnoses they had received. Participants also self reported their most recent $\mathrm{T}$ cell (CD4) count with cells coded as over and under 200 cells $\times 10^{6} / 1$ - the clinical criteria for AIDS, and viral load, with $<400$ copies $/ \mathrm{ml}$ coded as undetectable.

\section{Sexually transmitted infections}

We asked participants whether they had ever been treated for a sexually transmitted infection in order to obtain an estimate of lifetime STI prevalence. Participants also indicated whether they had been diagnosed with any of six STIs in the previous 3 months (90 days from the date of the assessment) and whether they had experienced any of three symptoms associated with STIs. Responses were used to group participants into those who had and had not experienced an STI or symptoms of an STI in previous 3 months.
Substance use

Participants were asked if they had used alcohol, marijuana, powder and "crack" cocaine, and injection drugs, or any other drugs in the previous 3 months. Responses to these items were coded for no use, use at least once a month, and use at least once a week.

\section{Sexual risk practices}

Participants were asked to report the number of times they had engaged in anal and vaginal intercourse without and with condoms in the past 3 months. We were particularly interested in unprotected anal and vaginal intercourse because of the high risk that these behaviours pose for HIV transmission. We also calculated the proportion of intercourse occasions protected by condoms using the formula (protected acts)/(total acts). Participants also recorded the number of sexual partners with whom they had engaged in each behaviour in the previous 3 months. Open response formats were used for the sexual behaviour measures to reduce response bias and to minimise measurement error. ${ }^{11}$ Measures similar to these have been found reliable. ${ }^{12}$

\section{STATISTICAL ANALYSES}

Participants were placed in one of three groups for comparisons (a) people who reported any STI or symptom of an STI in the previous 3 months; (b) sexually active people who did not report an STI or symptom of an STI in the previous 3 months; and (c) participants who were not sexually active in the past 3 months. Comparisons for demographic, health status, and substance use were performed using contingency table $\chi^{2}$ tests for nominal and ordinal data and one way analyses of variance (ANOVA) for continuous measures with planned comparisons conducted using least significant difference tests. For comparisons on measures of sexual behaviours, participants who reported an STI or STI symptoms were compared with individuals who did not report STIs using independent $t$ tests. Sexual behaviour variables were transformed to correct for extremely skewed distributions using the formula $\log _{10}(X+1)$, with observed values presented in the table. All statistical analyses used two tailed tests with $\mathrm{p}<0.05$. Univariate comparisons for substance use behaviours were followed by multiple logistic regression analyses for people reporting and not reporting an STI across sexes because the use of multiple substances was common in our sample.

\section{Results}

The majority of the sample was AfricanAmerican (79\%), with 19\% white participants, $2 \%$ Hispanic/Latino. Most participants (86\%) had annual incomes of less than $\$ 20000$. The mean age was 40.2 (SD 7.3, range 22-69), and the mean number of years of education was 12.7 (2.2), with $23 \%$ of participants reporting less than 12 years of education. Participants were aware of their HIV status for an average of 7.6 (4.8) years and had been hospitalised an average of 1.3 (1.8) times with an HIV associated condition. The mean CD4 cell count was 
Table 1 STI diagnoses and symptoms among men and women living with HIV-AIDS

\begin{tabular}{|c|c|c|c|c|c|c|}
\hline \multirow[b]{2}{*}{ STI diagnoses and symptoms } & \multicolumn{2}{|c|}{$\operatorname{Men}(n=228)$} & \multicolumn{2}{|c|}{ Women $(n=112)$} & \multicolumn{2}{|c|}{ Total $(n=340)$} \\
\hline & No & $\%$ & No & $\%$ & No & $\%$ \\
\hline \multicolumn{7}{|l|}{ Diagnoses } \\
\hline Gonorrhoea & 9 & 4 & 7 & 6 & 11 & 3 \\
\hline Chlamydia & 6 & 3 & 4 & 4 & 10 & 3 \\
\hline NGU & 1 & $>1$ & 1 & $>1$ & 2 & $>1$ \\
\hline Trichomonas & 2 & 1 & 10 & 9 & 12 & 4 \\
\hline Syphilis & 6 & 3 & 4 & 4 & 10 & 3 \\
\hline New HSV diagnosis & 7 & 3 & 7 & 6 & 14 & 4 \\
\hline Any STI & 24 & 11 & 18 & 16 & 42 & 12 \\
\hline \multicolumn{7}{|l|}{ Symptoms } \\
\hline Unexplained genital discharge & 5 & 2 & 19 & 17 & 22 & 6 \\
\hline Painful urination & 18 & 8 & 12 & 11 & 30 & 9 \\
\hline Genital ulcer & 11 & 5 & 10 & 9 & 21 & 6 \\
\hline Any STI symptoms & 29 & 13 & 35 & 31 & 64 & 19 \\
\hline Any STI diagnosis or symptom & 42 & 18 & 40 & 36 & 82 & 24 \\
\hline
\end{tabular}

$423.1 \times 10^{6} / 1(634.9) ; 91(27 \%)$ participants indicated that their viral load was undetectable at most recent testing and $237(69 \%)$ had either been diagnosed with an AIDS related condition or had a CD 4 count under 200 cells $\times 10^{6} / 1$.

PREVALENCE OF STIs

For the entire sample, $42(12 \%)$ participants reported an STI in the past 3 months and 40 (11\%) experienced symptoms of an STI without indicating a specific diagnosis in that time. Therefore, a total of $82(24 \%)$ participants were defined as having an STI or symptoms of an STI in the previous 3 months. Rates of specific STIs and STI symptoms for men and women are shown in table 1. Among men, gonorrhoea, chlamydia, syphilis, and newly diagnosed HSV were the most commonly reported STIs. Among women, trichomonas, gonorrhoea, and newly diagnosed HSV were most commonly identified. Symptoms of STIs were also reported differentially for men and women, with men most often reporting painful urination and women most often reporting an unexplained genital discharge. Analyses showed that women were significantly more likely than men to report an STI or STI symptom in the previous 3 months, $\chi^{2}(\mathrm{df}=1, \mathrm{n}=$ $340)=12.27, \mathrm{p}<0.001$.

Comparisons of people reporting a recent STI, people who were sexually active but not reporting an STI, and people who were not sexually active on demographic and health sta- tus characteristics showed significant differences for years of education, $\mathrm{F}(2,336)=3.9$, $\mathrm{p}<0.05$, and age, $\mathrm{F}(2,336)=8.1, \mathrm{p}<0.001$. Planned comparisons showed that people with STIs were less educated than their sexually active counterparts and younger than people who were not sexually active. Among men and women there were also differences between groups in incomes under $\$ 20000$ per year, but the differences were small and of limited practical significance. No other differences between groups were significant (see table 2).

SUBSTANCE USE AND STIs

Analyses showed that men who had recently had an STI were significantly more likely to have used powder forms of cocaine, $\chi^{2}(\mathrm{df}=4$, $\mathrm{n}=223)=13.7, \mathrm{p}<0.01$, crack cocaine, $\chi^{2}(\mathrm{df}$ $=4, \mathrm{n}=223)=14.3, \mathrm{p}<0.01$, and use of any non-alcoholic drug in the past 3 months, $\chi^{2}$ (df $=2, \mathrm{n}=224)=10.1, \mathrm{p}<0.01$, compared with men who did not have an STI. Among women, having had an STI was not associated with the use of any single type of drug, although women who reported a recent STI were significantly more likely to have used non-alcoholic drugs in the past 3 months, $\chi^{2}(\mathrm{df}=2, \mathrm{n}=112)=22.9$, $\mathrm{p}<0.01$. Collapsing across sexes, people with a recent STI were significantly more likely to use powder forms of cocaine, $\chi^{2}(\mathrm{df}=4, \mathrm{n}=335)$ $=13.9, \mathrm{p}<0.01$, crack cocaine, $\chi^{2}(\mathrm{df}=4, \mathrm{n}=$ $337)=16.9, \mathrm{p}<0.01$, and any non-alcoholic drug, $\chi^{2}(\mathrm{df}=2, \mathrm{n}=336)=11.6, \mathrm{p}<0.01$, compared with people who did not have an STI (see table 3). When all of the individual substance use variables were included in a multiple logistic regression analysis, only use of crack cocaine predicted having had an STI, OR $=1.6,95 \% \mathrm{CI}=1.1-2.6$.

SEXUAL RISK BEHAVIOURS

Analyses showed that men who had recently had an STI engaged in significantly more unprotected vaginal intercourse, $t(226)=2.9$, $\mathrm{p}<0.01$, significantly more unprotected anal intercourse, $t(226)=2.2, \mathrm{p}<0.05$, and significantly less condom use during anal intercourse, $t(95)=1.97, \mathrm{p}<0.05$, than men who did not have an STI. For women, analyses failed to show any significant differences

Table 2 Demographic and health characteristics of men and women living with HIV-AIDS and diagnoses or symptoms of an STI in the past 3 months

\begin{tabular}{|c|c|c|c|c|c|c|c|c|c|c|c|c|c|c|c|}
\hline & \multicolumn{6}{|l|}{ Men } & \multirow[b]{3}{*}{$p$} & \multicolumn{6}{|c|}{ Women } & \multirow[b]{3}{*}{$p$} & \multirow[b]{3}{*}{$p^{a}$} \\
\hline & \multicolumn{2}{|c|}{$\begin{array}{l}\text { Not sexually } \\
\text { active }(n=61)\end{array}$} & \multicolumn{2}{|c|}{$\begin{array}{l}\text { Sexually active } \\
\text { no } S T I(n=124)\end{array}$} & \multicolumn{2}{|c|}{$\begin{array}{l}\text { Sexually active } \\
\text { with STI }(n=42)\end{array}$} & & \multicolumn{2}{|c|}{$\begin{array}{l}\text { Not sexually } \\
\text { active }(n=26)\end{array}$} & \multicolumn{2}{|c|}{$\begin{array}{l}\text { Sexually active } \\
\text { no } S T I(n=46)\end{array}$} & \multicolumn{2}{|c|}{$\begin{array}{l}\text { Sexually active } \\
\text { with } S T I(n=40)\end{array}$} & & \\
\hline & No & $\%$ & No & $\%$ & No & $\%$ & & No & $\%$ & No & $\%$ & No & $\%$ & & \\
\hline Ethnic minority & 49 & 80 & 90 & 73 & 35 & 83 & ns & 24 & 92 & 44 & 96 & 34 & 85 & ns & ns \\
\hline Income $<\$ 20000$ & 56 & 92 & 96 & 78 & 37 & 88 & 0.05 & 24 & 92 & 37 & 82 & 40 & 100 & 0.01 & 0.01 \\
\hline \multicolumn{16}{|l|}{ Sexual orientation } \\
\hline Homosexual & 33 & 54 & 79 & 64 & 25 & 61 & & 3 & 12 & 7 & 15 & 1 & 3 & & \\
\hline Bisexual & 7 & 12 & 16 & 13 & 5 & 12 & & 3 & 12 & 3 & 7 & 3 & 8 & & \\
\hline Heterosexual & 21 & 34 & 29 & 23 & 11 & 72 & ns & 20 & 77 & 36 & 78 & 34 & 90 & ns & ns \\
\hline \multirow[t]{2}{*}{ AIDS diagnosis } & 41 & 84 & 81 & 83 & 32 & 91 & ns & 21 & 88 & 29 & 78 & 33 & 92 & ns & ns \\
\hline & Mean & $S D$ & $\overline{M e a n}$ & $S D$ & $\overline{M e a n}$ & $S D$ & & Mean & $S D$ & $\overline{M e a n}$ & $S D$ & Mean & $S D$ & & \\
\hline$\overline{\text { Age }}$ & 41.9 & 6.8 & 40.4 & 7.4 & 38.3 & 6.8 & 0.05 & 41.4 & 8.6 & 39.7 & 6.9 & 38.8 & 7.2 & ns & 0.01 \\
\hline Education & 12.8 & 2.1 & 13.4 & 2.3 & 12.2 & 2.0 & 0.01 & 11.7 & 1.8 & 12.5 & 2.2 & 11.7 & 2.4 & ns & 0.01 \\
\hline Years HIV positive & 7.8 & 5.5 & 7.9 & 4.6 & 7.8 & 5.3 & ns & 4.9 & 2.8 & 6.8 & 4.5 & 7.6 & 4.4 & 0.05 & ns \\
\hline CD 4 count $\left(\times 10^{6} / 1\right)$ & 368 & 374 & 400 & 482 & 282 & 339 & ns & 448 & 312 & 498 & 256 & 629 & 1584 & ns & ns \\
\hline Log viral load & 3.6 & 2.1 & 3.4 & 1.8 & 4.0 & 1.4 & ns & 3.3 & 2.2 & 2.5 & 2.1 & 2.8 & 2.2 & ns & ns \\
\hline
\end{tabular}

$\mathrm{p}$ for differences within sex groups and $\mathrm{p}^{\mathrm{a}}$ for differences between STI groups collapsing across sexes. 
Table 3 Substance use among men and women living with HIV-AIDS and diagnoses/symptoms of an STI in the past 3 months

\begin{tabular}{|c|c|c|c|c|c|c|c|c|c|c|c|c|c|c|c|}
\hline & \multicolumn{6}{|c|}{ Men } & \multirow[b]{3}{*}{$p$} & \multicolumn{6}{|c|}{ Women } & \multirow[b]{3}{*}{$p$} & \multirow[b]{3}{*}{$p^{a}$} \\
\hline & \multicolumn{2}{|c|}{$\begin{array}{l}\text { Not sexually } \\
\text { active }(n=61)\end{array}$} & \multicolumn{2}{|c|}{$\begin{array}{l}\text { Sexually active } \\
\text { no } S T I \\
(n=124)\end{array}$} & \multicolumn{2}{|c|}{$\begin{array}{l}\text { Sexually active } \\
\text { with } S T I \\
(n=42)\end{array}$} & & \multicolumn{2}{|c|}{$\begin{array}{l}\text { Not sexually } \\
\text { active }(n=26)\end{array}$} & \multicolumn{2}{|c|}{$\begin{array}{l}\text { Sexually active } \\
\text { no } S T I(n=46)\end{array}$} & \multicolumn{2}{|c|}{$\begin{array}{l}\text { Sexually active } \\
\text { with STI } \\
(n=40)\end{array}$} & & \\
\hline & No & $\%$ & No & $\%$ & No & $\%$ & & No & $\%$ & No & $\%$ & No & $\%$ & & \\
\hline \multicolumn{16}{|l|}{ Alcohol } \\
\hline None & 32 & 52 & 47 & 38 & 17 & 41 & & 21 & 80 & 33 & 72 & 21 & 54 & & \\
\hline Monthly & 12 & 20 & 27 & 22 & 8 & 18 & & 4 & 15 & 6 & 13 & 6 & 15 & & \\
\hline Weekly & 17 & 28 & 50 & 40 & 17 & 41 & $\mathrm{~ns}$ & 1 & 5 & 7 & 15 & 12 & 31 & $\mathrm{~ns}$ & $\mathrm{~ns}$ \\
\hline \multicolumn{16}{|l|}{ Marijuana } \\
\hline None & 47 & 78 & 84 & 68 & 31 & 76 & & 24 & 92 & 44 & 96 & 31 & 80 & & \\
\hline Monthly & 5 & 8 & 17 & 14 & 3 & 7 & & 0 & & 0 & & 2 & 5 & & \\
\hline Weekly & 8 & 14 & 22 & 18 & 7 & 17 & $\mathrm{~ns}$ & 2 & 8 & 2 & 4 & 6 & 15 & ns & $\mathrm{ns}$ \\
\hline \multicolumn{16}{|l|}{ Powder cocaine } \\
\hline None & 51 & 86 & 98 & 80 & 30 & 73 & & 25 & 96 & 44 & 96 & 35 & 87 & & \\
\hline Monthly & 5 & 9 & 15 & 12 & 1 & 3 & & 0 & & 1 & 2 & 1 & 3 & & \\
\hline Weekly & 3 & 5 & 10 & 8 & 10 & 25 & .01 & 1 & 4 & 1 & 2 & 4 & 10 & $\mathrm{~ns}$ & .01 \\
\hline \multicolumn{16}{|l|}{ Crack cocaine } \\
\hline None & 53 & 88 & 96 & 78 & 29 & 69 & & 24 & 92 & 42 & 91 & 29 & 73 & & \\
\hline Monthly & 2 & 4 & 10 & 8 & 0 & & & 0 & & 1 & 2 & 2 & 5 & & \\
\hline Weekly & 5 & 8 & 17 & 14 & 13 & 31 & .01 & 2 & 8 & 3 & 7 & 9 & 22 & .01 & .01 \\
\hline \multicolumn{16}{|l|}{ Injection drugs } \\
\hline None & 60 & 98 & 121 & 97 & 41 & 98 & & 26 & 100 & 46 & 100 & 39 & 99 & & \\
\hline Monthly & 1 & 2 & 2 & 2 & 0 & & & 0 & & 0 & & 1 & 1 & & \\
\hline Weekly & 0 & & 1 & 1 & 1 & 2 & $\mathrm{~ns}$ & 0 & & 0 & & 0 & & & $\mathrm{~ns}$ \\
\hline Any non-alcohol drug & 16 & 27 & 64 & 52 & 18 & 43 & .01 & 3 & 12 & 4 & 9 & 20 & 50 & .01 & .01 \\
\hline
\end{tabular}

$\mathrm{p}$ for differences within sex groups and $\mathrm{p}^{\mathrm{a}}$ for differences between STI groups collapsing across sexes.

between women who had an STI and women who did not have an STI in the past 3 months on any of the sexual risk behaviours. Collapsing across sexes, people with a recent STI reported significantly more unprotected vaginal intercourse, $t(336)=3.3, \mathrm{p}<0.001$, more condom protected vaginal intercourse, $t(337)=2.2, \mathrm{p}$ $<0.05$, more total acts of vaginal intercourse, $t$ $(337)=3.5, \mathrm{p}<0.01$, and significantly less condom use during anal intercourse, $t(104)=$ $2.2, \mathrm{p}<0.05$, than people who did not have an STI (see table 4).

\section{Discussion}

This study found that $12 \%$ of HIV infected people reported having an STI in the previous 3 months and an additional $11 \%$ reported symptoms possibly indicating an STI without an STI diagnosis. This point prevalence estimate of STIs among men and women living with HIV-AIDS is, however, limited by the study reliance on self reported diagnoses and self reported symptoms. Undetected STIs are common, particularly among women, suggesting that our methodology may have underestimated the actual prevalence of STIs. Also, self reported STIs can be underestimated as a result of social response biases, ${ }^{11}$ suggesting that our results represent a lower bound point estimate of STI prevalence in people living with HIV-AIDS. The current study findings should therefore be considered preliminary and in need of confirmatory research using clinical and laboratory screening methods for diagnosing STIs. Another study limitation was our lack of information regarding recent use of antibiotics for treating and preventing opportunistic infections, as these treatments will also affect some STIs. In addition, our study was limited by our failing to identify the HIV status of participants' sex partners, a factor essential to estimating risks for new HIV infections.

Findings from the current study strongly indicate the need for confirmatory research using biological testing for STIs in community samples of people living with HIV-AIDS. Results showed that substance use, particularly crack cocaine use, might be a marker for STI risk in HIV positive people. Across sexes, individuals who had used crack cocaine in the previous 3 months were nearly twice as likely to have had an STI or symptoms of an STI relative to people who did not have an STI or symptoms. Our findings also indicated higher rates of unprotected vaginal intercourse, protected vaginal and anal intercourse, and less proportional use of condoms during anal intercourse among people living with HIV-AIDS

Table 4 Sexual practices among men and women living with HIV-AIDS and diagnoses or symptoms of an STI in the past 3 months

\begin{tabular}{|c|c|c|c|c|c|c|c|c|c|c|c|}
\hline & \multicolumn{4}{|l|}{ Men } & \multirow[b]{3}{*}{$p$} & \multicolumn{4}{|l|}{ Women } & \multirow[b]{3}{*}{$p$} & \multirow[b]{3}{*}{$p^{a}$} \\
\hline & \multicolumn{2}{|c|}{ No STI $(n=186)$} & \multicolumn{2}{|c|}{$S T I(n=42)$} & & \multicolumn{2}{|c|}{ No STI $(n=72)$} & \multicolumn{2}{|c|}{$S T I(n=40)$} & & \\
\hline & Mean & $S D$ & Mean & $S D$ & & Mean & $S D$ & Mean & $S D$ & & \\
\hline Unprotected vaginal intercourse & 0.5 & 2.3 & 3.2 & 11.9 & 0.03 & 3.4 & 13.2 & 5.0 & 10.6 & ns & 0.01 \\
\hline Vaginal intercourse with condoms & 1.0 & 5.7 & 1.1 & 2.8 & ns & 2.9 & 7.9 & 5.6 & 16.7 & ns & 0.03 \\
\hline Total vaginal intercourse & 1.5 & 6.3 & 4.3 & 12.3 & 0.06 & 6.3 & 14.9 & 10.6 & 19.6 & ns & 0.01 \\
\hline$\%$ vaginal protected & 64.0 & 40.1 & 62.0 & 41.3 & ns & 62.6 & 43.8 & 56.7 & 45.1 & ns & $\mathrm{ns}$ \\
\hline Unprotected anal intercourse & 1.3 & 3.9 & 3.8 & 10.5 & .03 & 0.1 & 0.4 & 0.1 & 0.2 & ns & ns \\
\hline Anal intercourse with condoms & 3.9 & 14.2 & 3.7 & 12.4 & $\mathrm{~ns}$ & 0.2 & 0.1 & 0.1 & 0.1 & $\mathrm{~ns}$ & ns \\
\hline $\begin{array}{l}\text { Total anal intercourse } \\
\text { Th }\end{array}$ & 5.2 & 15.2 & 7.4 & 22.4 & ns & 0.2 & 0.8 & 0.1 & 0.4 & ns & ns \\
\hline$\%$ anal protected & 68.3 & 34.7 & 50.6 & 36.8 & 0.05 & 58.3 & 49.2 & 33.3 & 57.7 & ns & 0.03 \\
\hline Number of partners & 2.3 & 4.4 & 3.5 & 8.0 & ns & 0.8 & 1.0 & 1.2 & 1.9 & $\mathrm{~ns}$ & ns \\
\hline
\end{tabular}

Note: Numbers represent frequencies for behaviours reported during the past 3 months; $\mathrm{p}$ for differences within sex groups and $\mathrm{p}^{\mathrm{a}}$ for differences between STI groups collapsing across sexes. 
who had an STI or STI symptoms. Consistent with previous research, ${ }^{3} 36 \%$ of HIV infected people reported engaging in unprotected intercourse in the previous 3 months. Given the suggested risks for STIs in our sample as well as the risks for transmitting treatment resistant strains of $\mathrm{HIV},{ }^{13}$ there is a need for HIV prevention interventions targeted to people who are already known to be infected with HIV. Interventions that focus on reducing substance use, reinforcing consistent condom use, and enhancing motivation to practise safer sex should be targeted to sexually active people with HIV. Interventions for people already infected but continuing risk practices will probably prove more efficient and cost effective than interventions that only target masses of uninfected people. ${ }^{14}$

The authors thank the AIDS Survival Project of Atlanta, James Austin, Webster Luke, Kari DiFonzo, Delores Simpson, Jef Buckles, Florence Kyomugrsha, and Michael DiMarco for their assistance with data collection. National Institute of Menta Health (NIMH) Grant R01-MH57624 and Center Grant P30 MH52776 supported this research.

Contributors: SCK served as the principal investigator on this study, directing its design, implementation, data analyses, and manuscript preparation; DR served as project coordinator, developing the participant recruitment and sampling scheme, establishing, and implementing study protocols, and interpreting the study findings; MC served as project director, maintaining quality assurance, managing data collection activities, and conceptualising study results.

1 De Rosa C, Marks G. Preventive counseling of HIV-positive men and self-disclosure of serostatus to sex partners: new
opportunities for prevention. Health Psych 1998;17:22431 .
2 Marks G, Burris S, Peterman TA. Reducing sexual transmission of HIV from those who know they are infected: the need for persor
AIDS 1999;13:297-306.

3 Kalichman SC. HIV transmission risk behaviors of men and women living with HIV-AIDS: prevalence, predictors, and emerging clinical interventions. Clin Psych: Science Pract 2000;7:32-47.

4 Aral SO. Heterosexual transmission of HIV: the role of other sexually transmitted infections and behavior in its epidemiology, prevention and control. Ann Rev Public Health 1993; 14:451-67.

5 Aral SO, Peterman TA. Measuring outcomes of behavioural interventions for STD/HIV prevention. Int $\mathcal{F}$ STD AIDS 1996;7(Suppl 2):30-8.

6 Bersoff-Matcha SJ, Horgan MM, Fraser VJ, et al. Sexually transmitted disease acquisition among women infected with human immunodeficiency virus type 1.7 Infect Dis with human immunc

7 Osewe PL, Peterman TA, Ransom RL, et al. Trends in the acquisition of sexually transmitted diseases among HIVpositive patients at STD clinics, Miami 1988-1992. Sex Transm Dis 1996;23:230-3.

8 Lewis DA, Forster GE, Goh B. Gonorrhoea in HIV seropositive homosexual men attending an east London genitourinary medicine clinic [Letter]. Genitourin Med 1996;72:74

9 Flateby G, Esklind A, Brekke T, et al. Steady sexual relationship with an HIV-positive partner and the progression rate to AIDS. AIDS 1996;10:1750-2.

10 Beck EJ, Mandalia S, Leonard K, et al. Case-control study of sexually transmitted diseases as cofactors for HIV-1 transsexually transmitted diseases as cofacto
mission. Int $\mathcal{F}$ STD AIDS 1996;7:34-8.

11 Catania JA, Gibson D, Chitwood D, et al. Methodological problems in AIDS behavioral research: influences on problems in AIDS behavioral research: influences on measurement error and participation bias in
sexual behavior. Psychol Bull 1990;108:339-62

12 Kauth MR, St Lawrence JS, Kelly JA. Reliability of retrospective assessments of sexual HIV risk behavior: a comparison of biweekly, 3-month, and 12-month self reports. AIDS Ed Prev 1991;3:207-14.

13 Hecht FM, Grant RM, Petropoulos CJ, et al. Sexual transmission of an HIV-1 variant resistant to multiple reverse-transcriptase and protease inhibitors. $\mathrm{N} \mathrm{Engl} \mathrm{f} \mathrm{Med}$ 1998;339:307-9.

14 Pinkerton SD, Abramson PR, Kalichman SC, et al. Secondary HIV transmission rates in a mixed-gender sample. Int $\mathcal{F}$ STD AIDS 2000;11:38-44. 